\title{
A Systematic Review on Algebraic Thinking in Education
}

\author{
Iskander R. Sibgatullin ${ }^{1 *}$ (D), Andrey V. Korzhuev ${ }^{2}$ (D), Elmira R. Khairullina ${ }^{3}$ (D), Albina R. Sadykova ${ }^{4}$ \\ Roza V. Baturina ${ }^{5}$ (D), Vera Chauzova ${ }^{6}$ \\ ${ }^{1}$ Department of Pedagogy of Higher Education, Kazan (Volga Region) Federal University, Kazan, RUSSIA \\ 2 Department of Medical and Biological Physics, I. M. Sechenov First Moscow State Medical University (Sechenov University), \\ Moscow, RUSSIA \\ ${ }^{3}$ Faculty of Design and Software Engineering, Kazan National Research Technological University, Kazan, RUSSIA \\ ${ }^{4}$ Department of Informatics, Management and Technology, Moscow City University, Moscow, RUSSIA \\ ${ }^{5}$ Department of Natural Sciences and Information Technologies, Kazan National Research Technical University Named after A. N. \\ Tupolev - KAI, Kazan, RUSSIA \\ ${ }^{6}$ Department of Foreign Languages, RUDN University, Moscow, RUSSIA
}

Received 4 November 2021 - Accepted 19 December 2021

\begin{abstract}
Algebraic thinking is a method of solving math problems that stresses the significance of general connections. Excellent algebraic thinking necessitates strong symbolization and generalization ability. Students aged 7 to 15 are at the Piaget thinking stage's formal operational stage. Teachers, especially those working with secondary school students, must be aware of how kids think and reason algebraically. A detailed literature review provides an overview of research on algebraic thinking. The goal of this study was to compile a list of full-text papers that presented empirical research on algebraic thinking. The "algebraic thinking" search phrase was used to search the ERIC and Scopus databases. A total of 36 studies were included in the review. The educational levels, participants, nations, research methodologies, study objectives, data collecting tools, and analytic approaches have all been considered in studies on algebraic thinking. The number of studies published has risen over time. 2019 was the year with the most studies. The majority of the research was carried out in the United States of America. The majority of the participants in the study were elementary and secondary school pupils. Teachers' knowledge, elements impacting algebraic thinking, relations, and comprehension, as well as measuring categories, were determined when the study was grouped according to the study's topic. The algebraic thinking exam was the most popular data gathering instrument. The qualitative technique was used in the study of algebraic thinking. The most common method was found to be qualitative analysis. While inferential statistics are preferred in quantitative techniques, latent class analysis, cluster analysis, and test development analysis are used depending on the study design. According to the results, it was stated that in-service or pre-service teacher training is needed for the development of algebraic thinking and non-routine activities such as games should be used in the classroom. In addition, it has been determined that teaching strategies such as geometry representation, multiple representation strategies, mental computational activity also improve algebraic thinking.
\end{abstract}

Keywords: algebraic thinking, primary school, preservice teacher, literature review

\section{INTRODUCTION}

Algebraic thinking frequently includes the process of generalizing mathematical procedures, and it increasingly deals with unknown numbers as it becomes more complicated. In terms of pattern detection and mathematical generalization, teachers should carefully steer pupils to algebraic thinking. The process of shifting

(c) 2022 by the authors; licensee Modestum. This article is an open access article distributed under the terms and conditions of the Creative Commons Attribution License (http://creativecommons.org/licenses/by/4.0/). 


\section{Contribution to the literature}

- A systematic analysis of the studies on algebraic thinking in the last 10 years will provide a perspective for future studies.

- In the studies carried out, the trends in the research methods, data collection tools, and analyses techniques will be determined.

- It will be determined at which educational level studies on algebraic thinking come to the fore.

from actual or mathematical contexts to structure is known as algebraic thinking. The evolution of humans' skills to grasp and employ symbols is part of this process. With the mathematical recognition of number patterns that the youngster starts to generalize, algebraic thinking develops. Good symbolization and generalization abilities are required for strong algebraic reasoning.

Algebra, according to Kaput (2008), is a cultural product, or a body of knowledge that is ingrained in educational institutions. Operations are syntactically directed operations on symbols in classical symbol systems. Generalization, conversion, and transformational algebra are the three strands of school algebra. Algebraic thinking is a method of approaching mathematical problems that emphasizes the importance of generic relationships.

Teachers must be aware of their pupils' algebraic thinking abilities when solving a mathematical issue. Teachers, particularly secondary school students, must comprehend how pupils think and reason algebraically. Students aged 7 to 15 are in the formal operational stage of the Piaget thinking stage. In the study of mathematics, problem-solving is especially important. When a student confronts a challenge, according to Gagne, they not only solve the problem but also learn something new.

Algebraic thinking entails mathematical reasoning inside an algebraic mental framework. It's also a way of thinking and reasoning that helps pupils prepare for mathematical thinking in other fields. Many pupils struggle to grasp the fundamental ideas of mathematics. Students have trouble deciphering the meanings of new symbols they come across.

There are no systematic literature reviews that specifically focus on algebraic reasoning. In contrast, systematic literature reviews tend to focus on the use of ICT and instructors' knowledge for algebraic thinking (Pincheira \& Alsina, 2021) and using ICT to develop algebraic thinking (Goulding \& Kyriacou, 2008). A systematic literature review is aimed to provide an overview for research-based studies on algebraic thinking. Answers to the following research questions were sought in this context:

1. How are the educational levels, participants, and countries distributed?

2. What research methods, study objectives, data collection instruments, and analysis techniques have been employed in algebraic thinking studies throughout the years?

3. What are the counclusions of the studies?

\section{THEORETICAL BACKGROUND}

Algebraic thinking often involves the process of generalizing arithmetic operations, and as it gets more complex, it deals with unknown quantities. The five categories of algebraic thinking are (a) generalization and formulation of arithmetic operations, (b) manipulation and transformation of certain equality problems through inverse operation and principal syntax, (c) analysis of mathematical structures, (d) relations and functions, including numbers and letters, and (e) algebraic language and representation (NCTM, 2000; Radford, 2000; Schliemann et al., 2013; Stephens et al., 2015; Usiskin, 1999).

Teachers should carefully guide students to algebraic thinking in terms of pattern recognition and mathematical generalization as they acquire arithmetic skills (Carraher et al., 2000). For example, students discover the property of multiplicative identity by exploring the concrete equation $5 \times 1=5$ in different quantities. They then recognize the value of any number multiplied by a number, the pattern leading to the rule that it retains its identity. Finally, they learn to generalize in the form $a \times 1=a$ using the same letter as the symbolic representation of the same number of any value (Lentz, 2018).

According to Kamol (2005), the basic indicators of algebraic thinking consist of three basic skills: notation, model (pattern), and variable. For these three skills, notation includes the skills to use tables, graphics, symbols, etc. given in the problem. The model consists of the ability to generalize and formulate patterns. The variable consists of the ability to comprehend the role of the variable in generalized numbers.

Numerous scholars have conducted investigations on the nature of algebraic thinking. Numerous studies concentrated on what individuals do and how their capacity for generalization and symbol usage grows. According to Lins (1992), algebraic thinking refers to the process of transitioning from actual or mathematical contexts to structure. This process entails the development of humans' abilities to comprehend and use symbols. Similarly, Kaput (2008) has argued that there are two fundamental aspects of algebraic thinking: 


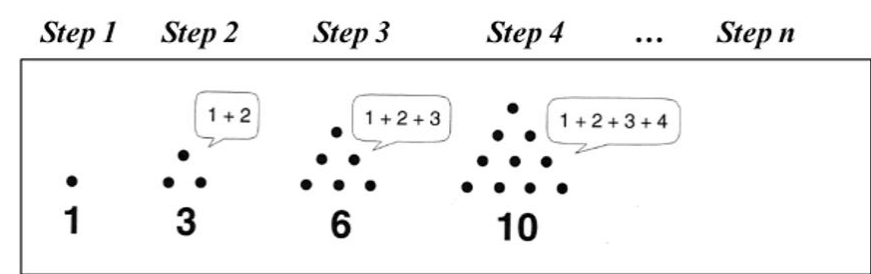

Figure 1. General pyramid pattern (Lentz, 2018)

(i) the dissemination and expression of increasingly generalizations, traditional symbol systems, and (ii) reasoning with symbolic forms, including syntactically directed manipulations of these forms (Pitta-Pantazi et al., 2019).

Algebraic thinking starts with the concrete experience of numbers and progresses to generalization and abstract thinking through activities (Mason, 2008; Radford \& Sabena, 2015). Even without access to academic language and symbolism, young children may have difficulty expressing their thoughts (Figure 1).

According to Mason (2008), when children begin to explore numbers, teachers will be able to use this natural curiosity to direct the meaning-making process to algebraic thinking. Thus, algebraic thinking develops with the arithmetic recognition of number patterns that the child begins to generalize. Over time and with targeted instruction, young students' algebraic thinking becomes more complex. Research shows that multiple studies in early algebra, many of which are long-term, have examined how well young students are able to solve algebraic growing pattern tasks by analyzing their discourse, work examples, and assessment results (Lentz, 2018).

What exactly are algebraic thinking skills, given that elementary school students are able to reason algebraically? Despite the overlapping but contradictory views of the definition of algebra and algebraic thinking, many agree that having strong algebraic thinking skills requires strong symbolization and generalization skills (Kaput, 2008). Carpenter and Levi (2000) defined algebraic thinking as "a) making generalizations and b) using symbols to represent mathematical ideas, represent and solve problems". Kaput (2008) focuses on Carpenter and Levi's (2000) definition of algebraic thinking as a conceptual framework to be used in studies. They conceptualized algebraic thinking as generalizing and symbolizing two different aspects, covering three stages: generalized arithmetic, functions and modeling (Kaput, 2008). The symbolizing aspect was defined as "systematically symbolizing generalizations of regularity and constraints", while the generalizing aspect was defined as "syntactic reasoning and actions regarding generalizations expressed in conventional symbol systems". This model, adapted for this particular study with primary school students, is shown in Figure 2. Simulation and generalization work are required in all three phases, but generalization work

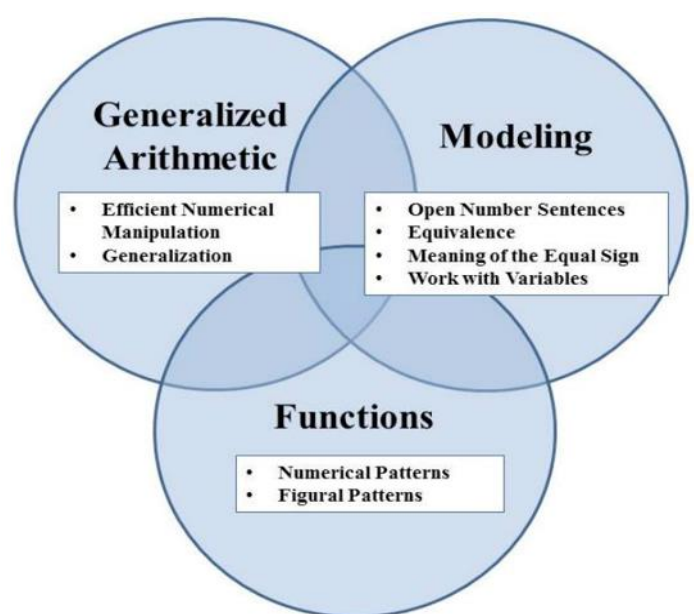

Figure 2. Algebraic thinking framework (Ralston, 2013)

may be more common in generalized arithmetic, whereas representation may be more common in modeling studies (Ralston, 2013).

According to Kaput (2008), algebra is a cultural product, that is, a body of knowledge embedded in education systems in the world, while algebraic thinking is a human activity, that is, from which activity algebra emerges. There are two primary parts to algebra in school. The first is how generalizations are created and generalized in increasingly systematic, traditional symbol systems. Second, in traditional symbol systems, they are syntactically guided operations on symbols. That is, students can perform certain operations in the $2 x+5 y=20$ equation. S/He further claims that these aspects are embodied in the three strands of school algebra: algebra as the study of structures and systems abstracted from calculations and relationships; algebra as the study of functions, relations, and combinations; and algebra (inside and outside of mathematics) as an implementation of a set of algebra modeling languages. Another school algebra model is proposed by Kieran (2006); here he identifies three main interrelated algebra activities: the generalization activity; conversion activity; and activity at global/meta level. Generalization activities, algebraic expressions and (i) equations representing quantitative problem situations; (ii) general expressions resulting from shape patterns or numerical sequences; and (iii) expressions of rules that determine numerical relationships. Transformational activities include syntactic manipulation of syntactically, including: collecting like terms; expanding brackets, simplifying expressions, exponentiation with polynomials, and solving equations. Global / meta-level activities include activities in which algebra is used as a tool and problem solving; modeling and forecasting, examining structure and change, analyzing relationships and generalizing and proving activities (Hodgen et al., 2018).

Algebraic thinking can be interpreted as an approach to quantitative situations that emphasize the aspect of 
general relations that can be used as cognitive tools to promote and retain more traditional school algebraic discourse, not necessarily symbols (Kieran, 2004). Some experts define algebraic thinking as a mental process such as "algebraic thinking, unknown reasoning, generalizing and formalizing the relationship between magnitude and developing the concept of variables". It can be interpreted that algebraic thinking is a mental process with something unknown, and it creates the formula of the relationship between the scale and the concept of variables (van Amerom, 2002). It is important for teachers to know students' algebraic thinking skills, especially secondary school students, in solving a mathematical problem. Teachers must understand how students think and reason algebraically. This is important for teachers to consider when giving materials such as linear programs, equations-inequalities, exponentials-logarithms, where the ability to use algebraic forms and algebraic solutions is required. This is important for understanding the development of students' thinking and reasoning to improve student learning in mathematics (Kamol \& Har, 2010).

According to Ntsohi (2013), algebraic thinking is the use of mathematical symbols and tools to represent information mathematically in terms of words, diagrams, tables, graphs and equations and to analyze different conditions such as unknown value placement, testing proofs, and searching for proofs. Kriegler (2007) states that there are two components in algebraic thinking, namely the development of mathematical thinking tools and the examination of the basic ideas of algebra. The mathematical thinking tool consists of three categories: problem-solving skills, representational skills, and quantitative reasoning abilities. The basic idea of algebra in question is algebra as a form of arithmetic generalization, algebra as the language of mathematics, and algebra as a tool for the function and modeling of mathematics. Algebra is essential in school time. However, algebra in adult life is important in that it is needed at work times even throughout life, human needs algebra (Kusumaningsih et al., 2018).

In the Piaget thinking stage, students aged 7-15 are in the formal operational stage. At this stage, people began to think about experience beyond concrete experience and to think more abstractly, ideally, and logically. Concrete operational thinkers must see the concrete elements $\mathrm{A}, \mathrm{B}$, and $\mathrm{C}$ to draw a logical conclusion if $\mathrm{A}=\mathrm{B}$ and $B=C$, then $A=C$. In contrast, the official operational thinker, this issue was presented verbally only (NCTM, 2000). Problems are something that is not separate from human life. Because the problem is the gap between hope and reality. People often wait, but it is not in line with real expectations. From a problem, people are not just a burden, problems mean finding new information. According to Gagne, if a student encounters a problem, they end up not only solving the problem but learning something new. Problem-solving becomes an important process in learning, especially in science and mathematics. Thus, problem-solving becomes one of the skills taught in learning. Problem-solving has special importance in the study of mathematics. Problemsolving is finding an appropriate way to achieve a goal. Given the importance of problem-solving, this is the reason why problem-solving has become central to learning mathematics. Students' mathematical abilities are classified as high, medium, and low. Students with high mathematical skills in solving algebra problems meet three indicators: non-structural level, multistructural level, and relational level. Students with mathematical skills fulfill two indicators; these are nonstructural and very structural (Schunk, 2012). Low mathematics students, on the other hand, are only acquainted with a non-structural level indicator. Based on the explanation, the author only takes the subject of research on high-skilled and intermediate students, as these students are high-skilled and can perform computation and analysis that can change variables appropriately using information clearly understood from the problem (Kusumaningsih et al., 2018).

According to Kieran (2011), algebraic thinking is not only about using symbols to express generality but also refers to slightly different situations that arise when individuals use all kinds of representations when they try to manipulate quantitative situations in a relational way. Radford (2000) also emphasized that algebraic thinking is not clear only when a precise symbolic language is acquired and applied; algebraic thinking requires individuals' efforts to represent generality, including gestures, verbal expressions, drawings, and alphanumeric symbols. As can be seen from these examples of approaches to algebraic thinking, the question of whether algebraic thinking should include alphanumeric symbols has been explored in previous years. Currently, most researchers agree that algebraic thinking is "not all about real symbols, but rather about ways of thinking" (Kieran, 2011). That is, analyzing relationships between quantities, recognizing the structure between quantities, examining changes, generalizing from specific events, solving problems, modeling, predicting, justifying, and proving (Kieran, 2004). This indicates a shift from a traditional view of algebra characterized by a specific content to a view of processes and forms of reasoning of algebraic thought (Chimoni et al., 2018).

Algebraic thinking includes mathematical reasoning in the algebraic framework of the mind and is also a type of thinking and reasoning that prepares students for mathematical thinking in other areas of mathematics (Kaput, 1999; Usiskin, 1999). However, studies show that students have difficulties in the algebraic thinking process and create many mistakes and misconceptions (Asquith et al., 2007; Herscovics \& Linchevscki, 1994; MacGregor \& Stacey, 1997). Many students have difficulty forming the basic concepts for algebra and 


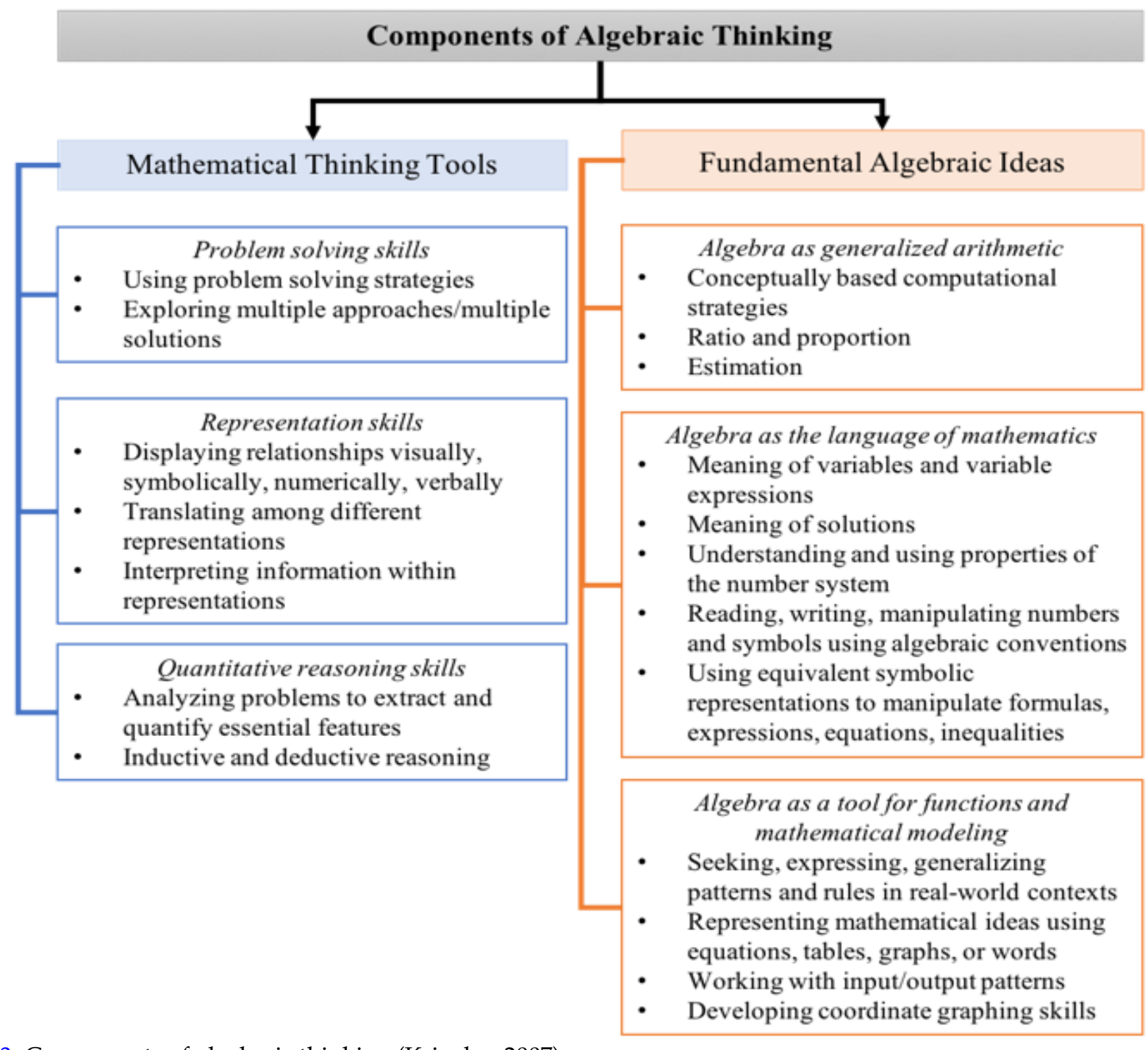

Figure 3. Components of algebraic thinking (Kriegler, 2007)

making connections between these concepts and the prealgebraic concepts they developed in primary school. In addition, students have difficulties in understanding the meanings of the new symbols they encounter. This situation causes students to be unsuccessful in the problem situations they encounter because of the symbols they do not understand (Herscovics \& Linchevscki, 1994).

Algebraic thinking; consists of three main skills: using symbols and algebraic relations, using multiple representations (such as symbolic, graphic, and table), and formulating generalizations (Wilkie, 2016). In addition, algebraic thinking, which is one of the principles and standards set by NCTM (2000) on mathematics education; requires understanding functions, representing and analyzing mathematical structures and situations in different ways using algebraic symbols, using mathematical models to represent quantitative relationships, and analyzing the change in different situations encountered in real life. Kaput (1999) summarized algebraic thinking in five items as follows. Algebraic thinking:
- Generalizing arithmetic and patterns,

- Using symbols meaningfully,

- Making the structure in the number system visible and abstracting by calculating,

- Working with functions, relationships, and joint exchange,

- It is a mathematical modeling process (Ayber \& Tanisli, 2017).

Kriegler (2007), on the other hand, examined algebraic thinking under two main headings, as seen in Figure 3. For each component, he defined the skills and areas of use of algebra. According to Herbert and Brown (1997), algebraic thinking; It is a process that requires the interpretation and analysis of mathematical information and the effective use of mathematical symbols and tools to find the unknown, verify assumptions and determine functional relationships. In this process, to define algebraic relations by selecting the necessary information from the available situations; reasoning proportionally; It is important to present mathematical information using different representations in order to 


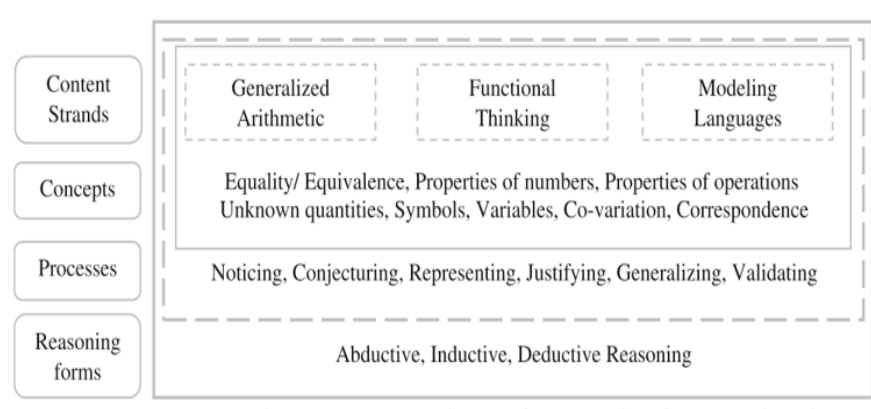

Figure 4. Basic dimensions describing algebraic thinking (Chimoni et al., 2018)

internalize concepts such as variable, equality, pattern, and function (Ayber \& Tanisli, 2017).

According to Smith and Thompson (2007), the world of mathematics consists primarily of the world of numbers and numerical operations (arithmetic), and then the world of symbols and symbolic procedures (algebra). From the beginning of their education life, students think arithmetic by performing arithmetic operations (addition, subtraction, multiplication, division) with numbers and reach unknown values with the help of known numbers.

As a result, it is seen that algebraic thinking can be defined more consistently on the basis of four different dimensions (Chimoni et al., 2018):

1. Examining structure and relationships in three algebra core content sequences: generalized arithmetic, functional thinking, and modeling (Kaput, 2008);

2. To understand basic algebraic concepts such as the equal sign, equality, equations, properties of numbers, properties of operations, variables, unknown quantities, symbols, co-variation, and correspondence.

3. Applying the method of investigating similarities and differences such as difference, expectation, representation, generalization, justification and confirmation, and validation of structures and relationships.

4. The use of reasoning forms such as abductive, inductive, and deductive reasoning that lead to conclusions (Figure 4).

Specifically, the development of algebraic thinking in early age groups will affect students' mathematics achievement in later ages. In the theoretical background, the scope and limits of algebraic thinking are expressed. However, how to develop algebraic thinking has been on the agenda of mathematics education researchers. In this context, it is aimed to analyze and synthesize researchbased publications on algebraic thinking.

\section{METHODS}

The current study is a scoping review of the existing literature on algebraic thinking. This review adhered to

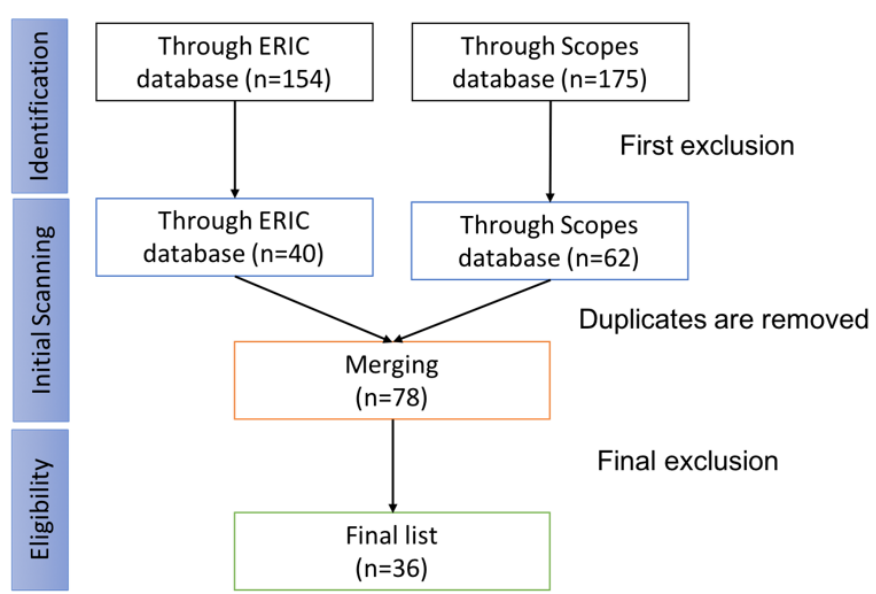

Figure 5. Flowchart describing the data collection process

the PRISMA guidelines (Liberati et al., 2009). PRISMA is a four-phase flow diagram, as illustrated in Figure 5. These sections detail the articles that were identified, included, and excluded, as well as the reasons for exclusions.

\section{Inclusion and Exclusion Criteria}

To accomplish the study objective, it is important to first identify related articles. The review's objective was to compile full-text publications reporting empirical research on algebraic thinking. To locate relevant publications, ERIC and Scopus, both of which are online databases, are chosen. ERIC is a comprehensive, userfriendly, searchable bibliographic and full-text database of education research and information that is accessible over the Internet. Scopus is the only abstract and citation database that combines a comprehensive, highly maintained abstract and citation database with enhanced data and connected academic literature from a broad range of fields. The ERIC and Scopus databases were searched using the phrase "algebraic thinking". Guided by the research questions, the following inclusion and exclusion criteria were applied:

1. The article must be published between January 2013 and September 2021. The period 2013-2021 was thus chosen.

2. We excluded articles that included literature reviews and theoretical studies.

3. Only peer review articles are included

4. Articles should be written in English.

5. The articles should be accessible as full-text.

\section{Data Analysis and Coding}

Relevant information was collected from 36 articles. Articles were coded and grouped into categories based on Table 1 to meet the research topics. 
Table 1 . Cotegory and code definitions

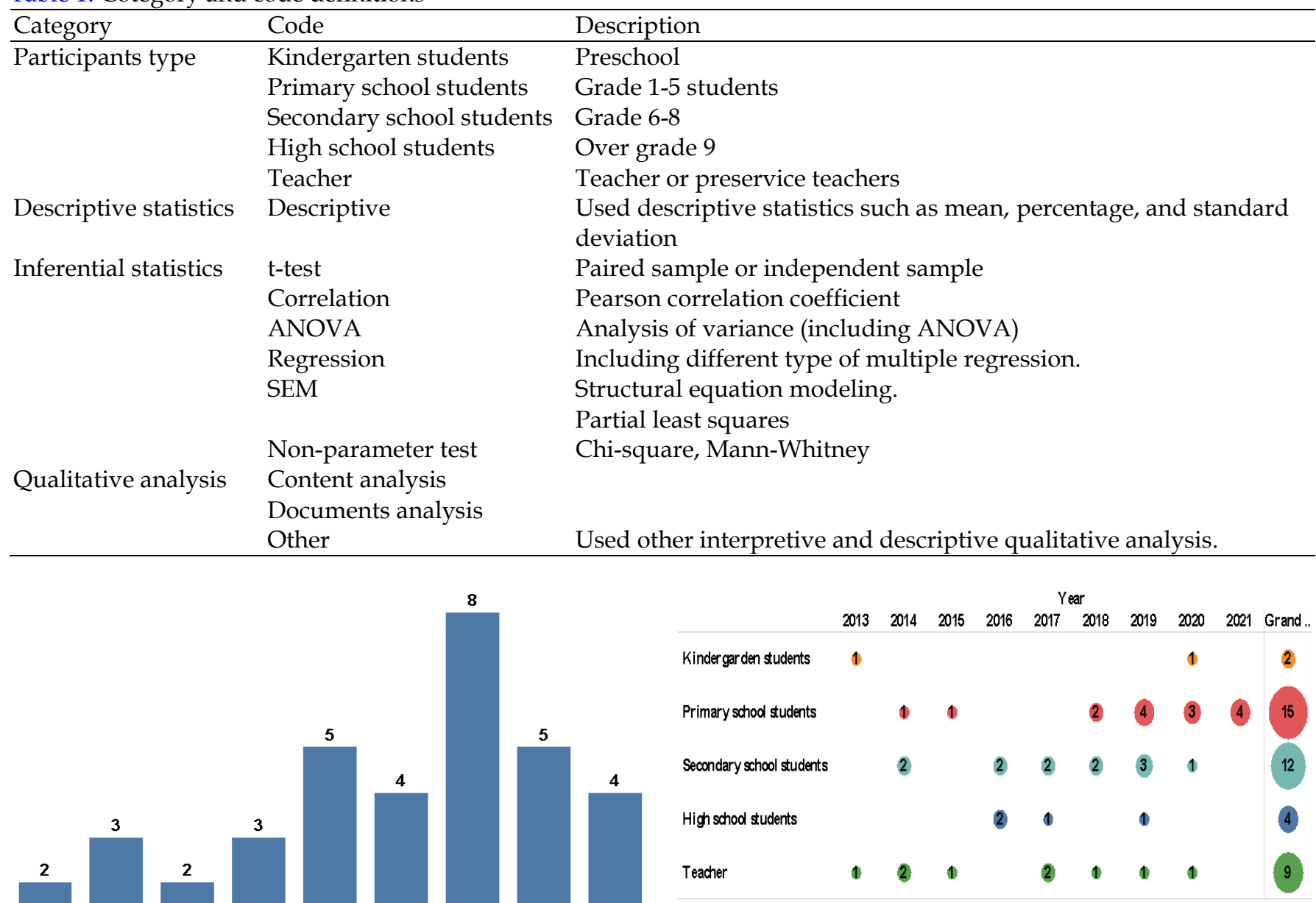

Figure 7. Distribution of participants over years

review sampled people from more than 15 countries. $38.8 \%$ of these studies were conducted in the United States of America $(n=14)$ and 11 percent in Indonesia $(\mathrm{n}=.4)$. It's worth noting that six of these studies (Apsari et al., 2020; Blanton et al., 2019; Demonty et al., 2018; Hitt et al., 2016, 2017; Ralston et al., 2018) were conducted in several countries, and so were counted numerous times in the statistics.

When the study was clustered according to the focus of the study, knowledge of teachers, factors affecting algebraic thinking, relations, and understanding and measuring categories were determined and shown in Table 2.

In the category of knowledge of teachers, the majority of the studies aimed to measure the level of knowledge of pre-service teachers about algebraic thinking. In two of the studies (Demonty et al., 2018; Wu, 2017), it was tried to determine the knowledge levels of the teachers. One study (Hunter \& Miller, 2020) focused on teachers' experiences in the classroom. Thirteen of the research examined variables impacting algebraic reasoning. Some studies (Afonso \& Mc Auliffe, 2019; Blanton et al., 2015; Mulligan et al., 2020; Papadopoulos \& Patsiala, 2019) have been conducted to determine the efficacy of applied programs, curricula, games and activities on algebraic 


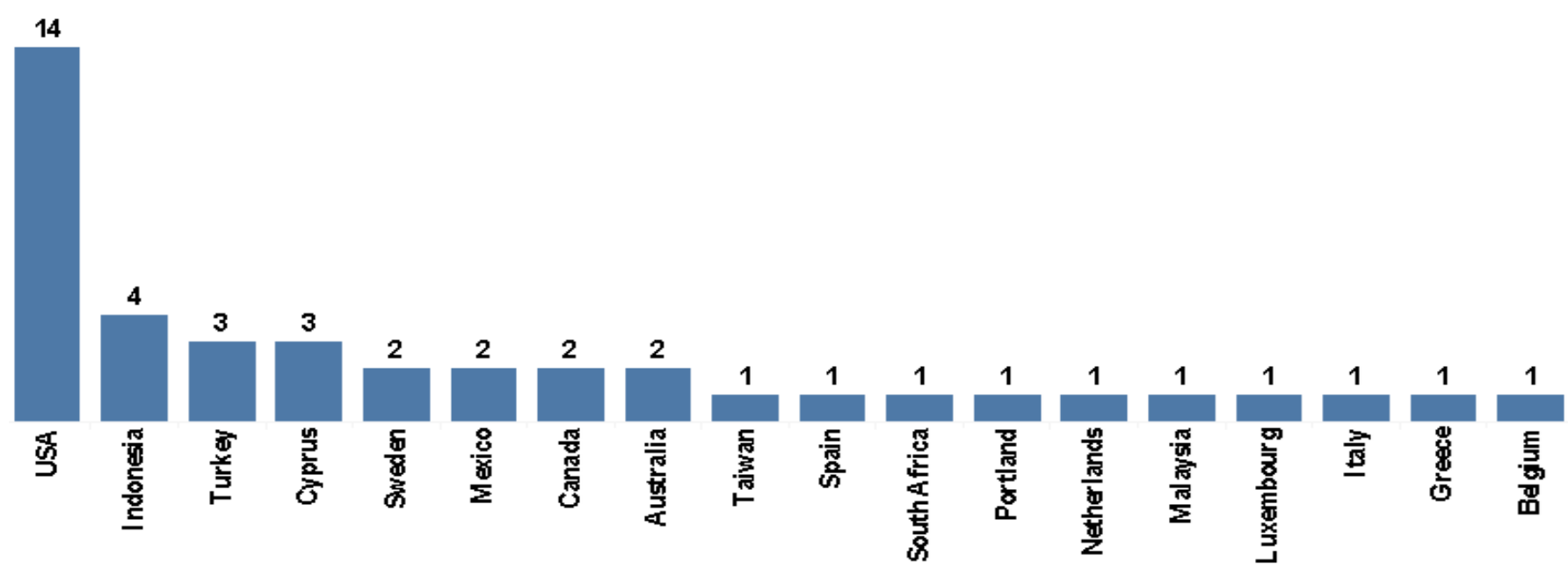

Figure 8. Graphical distribution of the study

Table 2. Clusters related to the focus of the study

\begin{tabular}{|c|c|c|}
\hline \multirow{2}{*}{\multicolumn{2}{|c|}{ Clusters Focus of studies }} & $\mathrm{N}$ \\
\hline & e of teachers & 8 \\
\hline & Knowledge of pre-service teacher & 5 \\
\hline & Knowledge of teachers & 2 \\
\hline & Exploratory teaching experiments & 1 \\
\hline \multicolumn{2}{|c|}{ Factors affecting algebraic thinking } & 13 \\
\hline & The effect of the programs & 1 \\
\hline & Implementation of mathematics curriculum & 1 \\
\hline & The effect of The Game & 1 \\
\hline & The effect of open questions & 1 \\
\hline & The effect of geometry representation & 1 \\
\hline & Role of pattern-based reasoning & 1 \\
\hline & Improving teaching material & 1 \\
\hline & Effect of cognitive factor on algebraic thinking & 1 \\
\hline & Ways of engaging children in algebraic thinking & 2 \\
\hline & Improving students' algebraic thinking ability & 1 \\
\hline & Emerging algebraic thinking & 1 \\
\hline & The way specific cognitive processes & 1 \\
\hline \multicolumn{3}{|c|}{ Relations } \\
\hline & Mental computational activity/algebraic thinking & 1 \\
\hline & $\begin{array}{l}\text { Assessment of young children's repeating pattern } \\
\text { knowledge }\end{array}$ & 1 \\
\hline & $\begin{array}{l}\text { The gap between arithmetic and algebraic } \\
\text { thinking }\end{array}$ & 1 \\
\hline & $\begin{array}{l}\text { Articulate between arithmetic thinking and the } \\
\text { early algebraic thinking }\end{array}$ & 1 \\
\hline & $\begin{array}{l}\text { Algebraic thinking competition performance and } \\
\text { mathematics achievements }\end{array}$ & 1 \\
\hline & Algebraic thinking and mathematical reasoning & 1 \\
\hline \multicolumn{3}{|c|}{ Understanding and measuring } \\
\hline & Understand the notion of early algebraic thinking & 1 \\
\hline & Investigating algebraic thinking & 1 \\
\hline & Early algebra instructional sequence & 1 \\
\hline & $\begin{array}{l}\text { Categorization of student responses in open- } \\
\text { ended questions }\end{array}$ & 1 \\
\hline & Measuring algebraic thinking & 1 \\
\hline & Students' errors & 1 \\
\hline & Develop an assessment of algebraic thinking & 1 \\
\hline & Determine how textbooks give importance & 1 \\
\hline & The validity of these algebraic thinking strands & 1 \\
\hline
\end{tabular}

thinking. Additionally, it was explored if the students' cognitive characteristics had an influence on their algebraic thinking (Chimoni \& Pitta-Pantazi, 2017; Somasundram, 2021). In the studies conducted in the relation category, the level of relationship between algebraic thinking and related concepts was investigated rather than an effect. In one study (Pourdavood et al., 2020), the relationship between mental computational activity and algebraic thinking was examined. In another study (Eriksson \& Sumpter, 2021), algebraic thinking and mathematical reasoning were investigated. The other focus of the studies was understanding and measuring algebraic thinking. Especially early algebraic thinking was encountered more frequently (Blanton et al., 2019; Chimoni et al., 2018). In addition, the measurement of algebraic thinking and the development of a scale related to it are among the publications (PittaPantazi et al., 2019; Ralston et al., 2018; Rittle-Johnson et al., 2013).

There are 16 elementary schools and 13 secondary schools where the majority of the research is being carried out (Figure 9). Seven of them are college or university. There are two studies (Mulligan et al., 2020; Rittle-Johnson et al., 2013) at the kindergarten level. Four study is undertaken at the high school level. Six studies (Chimoni \& Pitta-Pantazi, 2017; Chimoni et al., 2018; Hitt et al., 2016; Pitta-Pantazi et al., 2019; van den Kieboom et al., 2014; Wilkie, 2016) are being carried out at various educational levels.

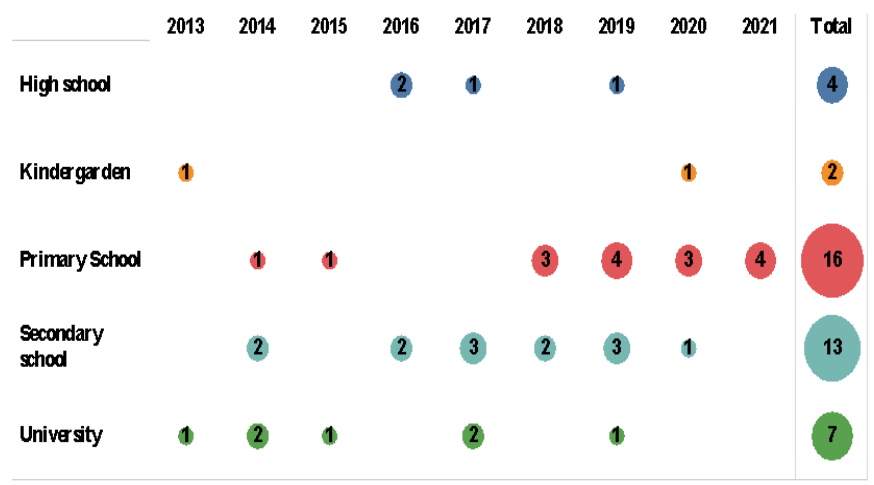

Figure 9. Educational level employed in studies 


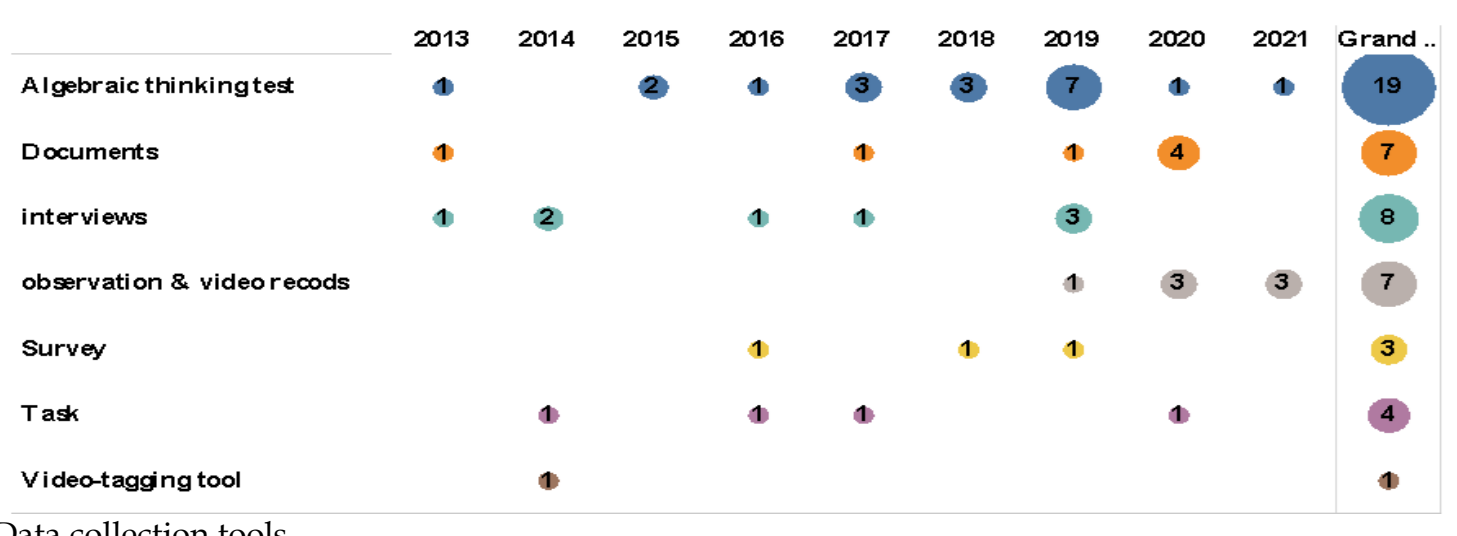

Figure 10. Data collection tools

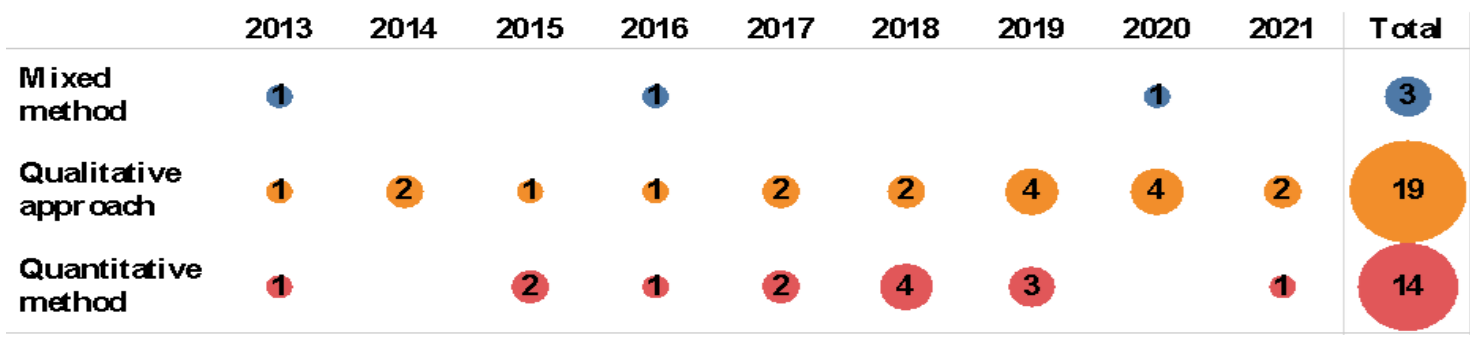

Figure 11. Research methods employed in studies-1

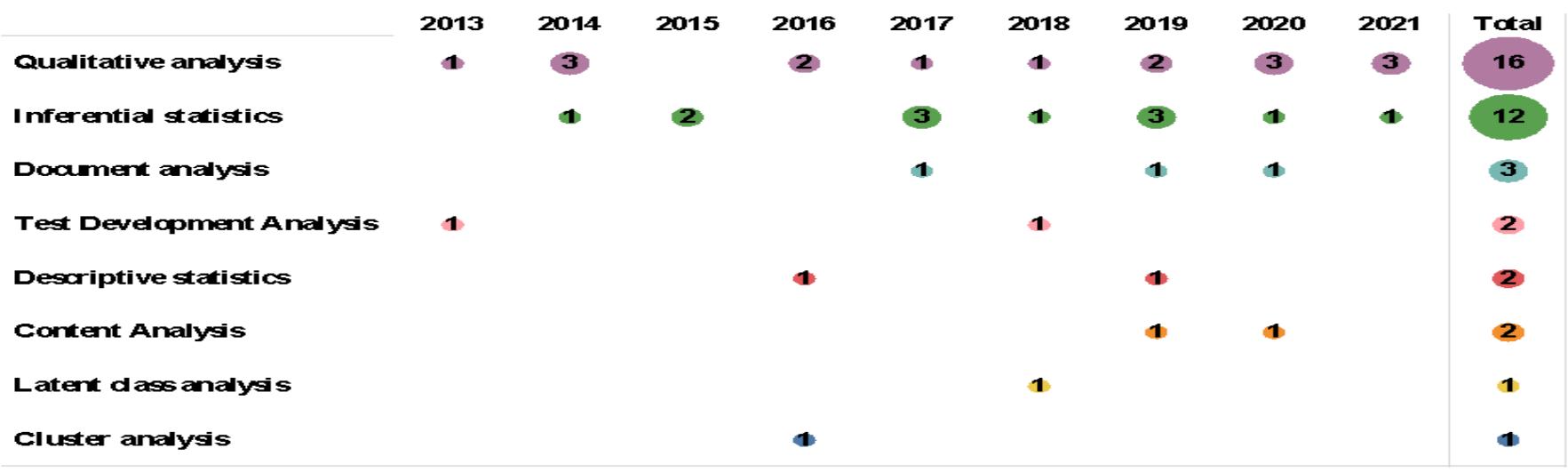

Figure 12. Research methods employed in studies-2

The most preferred data collection tool was the algebraic thinking test as seen from Figure 10. The least used measurement tool was data collection from preservice teachers with the video-tagging method (Walkoe, 2014). In many studies (Agoestanto et al., 2019; Apsari et al., 2020; Obara, 2019), "interview" has been used as a data collection tool to verify and support the data obtained. In-class observation (Afonso \& Mc Auliffe, 2019) and video recordings (Eriksson \& Eriksson, 2021; Eriksson \& Sumpter, 2021; Venenciano et al., 2020) were also used to determine the algebraic thinking levels of the students.

As shown in Figure 11, it was discovered that 52.7 percent of the research on algebraic thinking employed the qualitative approach, 38.9 percent employed the quantitative approach, while other studies chose the mixed method. The use of open-ended questions in the testing of algebraic thinking may be one of the factors that contribute to the preference for the qualitative method. When the distribution is broken down by year, it becomes clear that qualitative investigations are conducted on a yearly basis. Years have passed since any quantitative study was conducted.

When the chosen analytic techniques in the research were investigated, qualitative analysis was shown to be the most popular (Figure 12). However, document analysis and content analysis have been specifically acknowledged as analysis techniques in qualitative approaches. While inferential statistics are favored in quantitative approaches, depending on the study design, latent class analysis, cluster analysis, and test development analysis are chosen. Qualitative and test development studies gained prominence in 2013 and 2018. Its objective is to define algebraic thinking and to provide valid measuring tools. In the years that followed, several analyses were favored in investigations. 


\section{Conclusion of the Studies}

According to the conclusions of the studies, ways to start teaching algebraic thinking at early age should be explored. In this context, training and curricula should be prepared to improve the knowledge and experience of teachers and in-service teachers. In order to improve students' algebraic thinking, teachers should improve their communication (Demonty et al., 2018), support students to engage with higher levels of mathematical thinking (Hunter \& Miller, 2020) and nourishing problem-solving skills (Wu, 2017). Some research (Inan, 2015; Magiera et al., 2013; Walkoe, 2014) claimed that algebraic thinking among teacher candidates was satisfactory, while others (Magiera et al., 2017; van den Kieboom et al., 2014) said that it should be improved. The effects of teaching activities, the development of mathematical concepts, or teaching strategies on students' algebraic thinking were examined and concluded. Pattern tasks positively affect the algebraic thinking of the students (Afonso, 2019; Guler \& Celik, 2021; Mulligan et al., 2020; Obara, 2019; Syarifuddin \& Atweh, 2022; Walkowiak, 2014). Also, number sense (Adamuz-Povedano et al., 2021; Somasundram, 2021), operation sense (Somasundram, 2021), symbol sense (Somasundram, 2021), non-numerical quantities (Venenciano et al., 2020), positive integers (Eriksson \& Eriksson, 2021) and rational numbers (Eriksson \& Eriksson, 2021) have effect on the development of algebraic thinking. Also, geometry representation (Apsari et al., 2020), multiple representation strategies (Kusumaningsih et al., 2018), mental computational activity (Pourdavood et al., 2020), symmetry, and transformations activities (Mulligan et al., 2020) have effect on elementary school students' the algebraic thinking. Valid and reliable measurement tools have been developed to determine algebraic thinking (PittaPantazi et al., 2019; Ralston et al., 2018; Rudyanto et al., 2019).

\section{DISCUSSION}

The educational levels, participants, countries, research methodologies, study objectives, data collecting tools, and analysis techniques have all been considered in relation to algebraic thinking research. Over the years, the number of researches published has increased. The year with the most studies was 2019. In 2020 and 2021, the number of the studies decreases. The decline in numbers might be attributed to the increased difficulty in undertaking research-based studies as a result of the COVID-19.

The study was carried out mostly with primary school students and secondary school students. Algebraic thinking may develop in conjunction with numerical learning in both elementary and secondary education (Afonso \& Mc Auliffe, 2019; Demonty et al., 2018). Chimoni (2018) asserts that pupils can acquire algebraic thinking as early as elementary school provided the learning environment is conducive. The preceding may be a cause for researchers to do studies with elementary students. The research enrolled a small number of kindergarten students. However, as stated in many studies (Chimoni et al., 2018; Mulligan et al., 2020; Specht, 2005; Stephens et al., 2015), activities to be done in early age groups support the development of algebraic thinking in students.

The algebraic thinking test was the most often used data gathering technique. The least often utilized measuring instrument was video-tagging (Walkoe, 2014) data gathering from preservice teachers. Some studies (Agoestanto et al., 2019; Apsari et al., 2020; Obara, 2019) have employed "interview" as a data gathering strategy to verify and substantiate the data acquired. Additionally, in-class observation (Afonso \& Mc Auliffe, 2019) and video recordings (Eriksson \& Eriksson, 2021; Eriksson \& Sumpter, 2021; Venenciano et al., 2020) were employed to ascertain the students' algebraic thinking.

Teachers have an important role in the development of educational processes (Kyriacou, 2009). Studies evaluating the enhancement and enrichment of educational subject information should be shared in order to help students grow their algebraic thinking skills and abilities. One study (Hunter \& Miller, 2020) focused on teachers' experiences in the classroom. In the category of teacher knowledge, most research intended to assess pre-service teachers' algebraic thinking skills. Thirteen studies looked at factors affecting algebraic thinking. Some studies (Afonso \& Mc Auliffe, 2019; Blanton et al., 2015; Mulligan et al., 2020; Papadopoulos \& Patsiala, 2019) have been focused to determine the affecting factors on algebraic thinking. It was also investigated if the students' cognitive traits influenced their algebraic reasoning. In the relation category, rather than an impact, the amount of relationship between algebraic thinking and related ideas was explored. Among the papers are the measuring of algebraic thinking and the construction of a scale.

It was revealed that the majority of algebraic thinking study used a qualitative approach (Radford, 2000); nevertheless, the quantitative approach is also favored, and some studies used a mixed method approach. One of the variables that contribute to the choice for the qualitative technique is the use of open-ended questions (Di Paola et al., 2016) in the examination of algebraic thinking (Wilkie, 2016). When the data is split down by year, it is obvious that qualitative research is carried out on an annual basis. A quantitative research hasn't been undertaken in years. When the research's chosen analytic methodologies were examined, qualitative analysis was shown to be the most popular. Document analysis (Ayber \& Tanisli, 2017) and content analysis (Papadopoulos \& Patsiala, 2019), on the other hand, have been recognized as analytical tools in qualitative approaches. While inferential statistics are preferred in 
quantitative techniques, latent class analysis, cluster analysis, and test development analysis are used depending on the study design. In 2013 and 2018, qualitative and test development studies become more popular. Its goal is to characterize algebraic thinking and give useful methods for assessing it. Several interpretations were preferred in research in the years that followed.

The results of the research stress the necessity of developing algebraic thinking, especially at an early age. When regarded in this context, studies have been carried out in order to serve this purpose:

a. What the knowledge and skills that teachers or teacher candidates should have and how they change with the training given (Demonty et al., 2018; Inan, 2015; Magiera et al., 2013, 2017; van den Kieboom et al., 2014; Walkoe, 2014). According to Pincheira and Alsina (2021), teachers in early childhood and primary school demonstrate a lack of mathematical expertise necessary to teach early algebra. This result confirms the necessity of teacher training.

b. The focus was on developing activities, activities and strategies to improve students' algebraic thinking levels (Afonso, 2019; Gambari et al., 2016; Hunter \& Miller, 2020; Kusumaningsih et al., 2018; Mulligan et al., 2020; Obara, 2019; Pourdavood et al., 2020; Walkowiak, 2014; Wu, 2017). In the study conducted by Papadopoulos and Patsiala (2019), it was determined that activities such as games have a positive effect on students' algebraic thinking. In other words, non-routine activities should be done for the classroom in order to develop algebraic thinking.

c. The relevance of related mathematical concepts to algebraic thinking has been investigated (Adamuz-Povedano et al., 2021; Eriksson \& Eriksson, 2021; Somasundram, 2021; Venenciano et al., 2020). Number sense (Adamuz-Povedano et al., 2021; Somasundram, 2021), operation sense (Somasundram, 2021), symbol sense (Somasundram, 2021), non-numerical quantities (Venenciano et al., 2020), positive integers (Eriksson \& Eriksson, 2021) and rational numbers (Eriksson \& Eriksson, 2021) have effect on the development of algebraic thinking.

\section{CONCLUSIONS}

The purpose of this study was to build a collection of full-text articles that discussed empirical research on algebraic thought. The ERIC and Scopus databases were searched using the search term "algebraic thinking". The review includes a total of 36 papers. Numerous factors have been examined in studies on algebraic thinking, including educational levels, participants, nations, research procedures, study objectives, data collection tools, and analytic approaches. The number of published researches has increased over time. The year 2019 saw the greatest number of studies. The research was conducted mostly in the United States of America. The study's majority of participants were elementary and secondary school students. Teachers' knowledge, the factors affecting algebraic thinking, relations, and comprehension, as well as the measurement categories, were identified when the study was classified according to its theme. The algebraic reasoning examination was the most often used data collection instrument. In the study of algebraic thinking, the qualitative approach was applied. Qualitative analysis was shown to be the most often used technique. While inferential statistics are preferable in quantitative approaches, depending on the research design, latent class analysis, cluster analysis, and test development analysis may be utilized. According to the results, it was stated that in-service or pre-service teacher training is needed for the development of algebraic thinking and non-routine activities such as games should be used in the classroom. In addition, it has been determined that teaching strategies such as geometry representation, multiple representation strategies, mental computational activity also improve algebraic thinking.

\section{Recommendations}

Mathematics teacher educators should organize training on how to develop algebraic thinking skills especially in younger age group teachers. This issue should be brought to the attention of pre-service instructors. In future research, it can be studied how an effective in-service training should be. In addition, nonroutine activities are recommended in classroom practices. It is recommended for future researchers to synthesize those that have a positive effect in applications to develop algebraic thinking.

\section{Limitations of the Study}

This study is limited to the articles indexed in the ERIC and SCOPUS databases at the time the internet search was made. It is possible that there will be studies that will contribute to this topic.

Author contributions: All authors have sufficiently contributed to the study, and agreed with the results and conclusions.

Funding: This paper has been supported by the Kazan Federal University Strategic Academic Leadership Program.

Declaration of interest: No conflict of interest is declared by authors.

\section{REFERENCES}

Adamuz-Povedano, N., Fernández-Ahumada, E., Teresa García-Pérez, M., \& Montejo-Gámez, J. (2021). Developing number sense: An approach to initiate algebraic thinking in primary education. 
Mathematics, 9(5), 1-25. https://doi.org/10.3390/ math 9050518

Afonso, D. G. (2019). The development of algebraic thinking in the foundation phase: A comparative study of two different curricula. Cape Peninsula University of Technology.

Afonso, D., \& Mc Auliffe, S. (2019). Children's capacity for algebraic thinking in the early grades. African Journal of Research in Mathematics, Science and Technology Education, 23(2), 219-232. https:// doi.org/10.1080/18117295.2019.1661661

Agoestanto, A., Sukestiyarno, Y. L., Isnarto, Rochmad, \& Lestari, M. D. (2019). The position and causes of students errors in algebraic thinking based on cognitive style. International Journal of Instruction, 12(1), 1431-1444. https://doi.org/10.29333/ iij.2019.12191a

Apsari, R. A., Putri, R. I. I., Sariyasa, Abels, M., \& Prayitno, S. (2020). Geometry representation to develop algebraic thinking: A recommendation for a pattern investigation in pre-algebra class. Journal on Mathematics Education, 11(1), 45-58. https://doi.org/10.22342/jme.11.1.9535.45-58

Asquith, P., Stephens, A. C., Knuth, E. J., \& Alibali, M. W. (2007). Middle school mathematics teachers' knowledge of students' understanding of core algebraic concepts: Equal sign and variable. Mathematical Thinking and Learning, 9(3), 249-272. https:// doi.org/10.1080/10986060701360910

Ayber, G., \& Tanisli, D. (2017). An analysis of middle school mathematics textbooks from the perspective of fostering algebraic thinking through generalization. Kuram ve Uygulamada Egitim Bilimleri [Educational Sciences in Theory and Practice], 17(6), 2001-2030. https://doi.org/10.12738/ estp.2017.6.0506

Blanton, M., Isler-Baykal, I., Stroud, R., Stephens, A., Knuth, E., \& Gardiner, A. M. (2019). Growth in children's understanding of generalizing and representing mathematical structure and relationships. Educational Studies in Mathematics, 102(2), 193-219. https://doi.org/10.1007/s10649019-09894-7

Blanton, M., Stephens, A., Knuth, E., Gardiner, A. M., Isler, I., \& Kim, J. S. (2015). The development of children's algebrai thinking: The impact of a comprehensive early algebra intervention in third grade. Journal for Research in Mathematics Education, 46(1), 39-87. https://doi.org/10.5951/jresemath educ.46.1.0039

Carpenter, T. P., \& Levi, L. (2000). Developing conceptions of algebraic reasoning in the primary grades. Research Report. In Research Report: National Center for Improving Student Learning and
Achievement in Mathematics and Science. https:/ / eric.ed.gov/?id=ED470471

Carraher, D. W., Schliemann, A., \& Brizuela, B. M. (2000). Early algebra, early arithmetic: Treating operations as functions. Pme-Na, XXII, 1-26.

Chimoni, M., \& Pitta-Pantazi, D. (2017). Parsing the notion of algebraic thinking within a cognitive perspective. Educational Psychology, 37(10), 11861205. https:// doi.org/10.1080/01443410.2017. 1347252

Chimoni, M., Pitta-Pantazi, D., \& Christou, C. (2018). Examining early algebraic thinking: Insights from empirical data. Educational Studies in Mathematics, 98(1), 57-76. https://doi.org/10.1007/s10649-0189803-x

Demonty, I., Vlassis, J., \& Fagnant, A. (2018). Algebraic thinking, pattern activities and knowledge for teaching at the transition between primary and secondary school. Educational Studies in Mathematics, 99(1). https://doi.org/10.1007/ s10649-018-9820-9

Di Paola, B., Battaglia, O. R., \& Fazio, C. (2016). Nonhierarchical clustering as a method to analyse an open-ended questionnaire on algebraic thinking. South African Journal of Education, 36(1), 1-13. https:// doi.org/10.15700/saje.v36n1a1142

Eriksson, H., \& Eriksson, I. (2021). Learning actions indicating algebraic thinking in multilingual classrooms. Educational Studies in Mathematics, 106(3), 363-378. https://doi.org/10.1007/s10649020-10007-y

Eriksson, H., \& Sumpter, L. (2021). Algebraic and fractional thinking in collective mathematical reasoning. Educational Studies in Mathematics. https:// doi.org/10.1007/s10649-021-10044-1

Gambari, A. I., Shittu, A. T., \& Taiwo, O. A. (2016). Enhancing students' understanding of algebra concepts through cooperative computer instruction. Pedagogical Research, 1(2), 55. https:/ / doi.org/10.20897/lectito.201655

Goulding, M., \& Kyriacou, C. (2008). A systematic review of the use of ICTs in developing pupils' understanding of algebraic ideas. EPPI-Centre Report, 1606.

Guler, M., \& Celik, D. (2021). The effect of an elective algebra teaching course on prospective mathematics teachers' pedagogical content knowledge. International Electronic Journal of Mathematics Education, 16(2), em0636. https:// doi.org/10.29333/iejme/10902

Herbert, K., \& Brown, R. H. (1997). Patterns as tools. Teaching Children Mathematics, 3(1997), 340-345. https:// doi.org/10.5951/TCM.3.6.0340 
Herscovics, N., \& Linchevscki, L. (1994). A cognitive gap between arithmetic and algebra. Educational Studies, 27(1), 59-78. https:/ / doi.org/10.1007/BF01284528

Hitt, F., Saboya, M., \& Cortés Zavala, C. (2016). An arithmetic-algebraic work space for the promotion of arithmetic and algebraic thinking: Triangular numbers. ZDM, 48(6), 775-791. https://doi.org/ $10.1007 /$ s11858-015-0749-5

Hitt, F., Saboya, M., \& Zavala, C. C. (2017). Rupture or continuity: The arithmetico-algebraic thinking as an alternative in a modelling process in a paper and pencil and technology environment. Educational Studies in Mathematics, 94(1), 97-116. https: / / doi.org/10.1007/s10649-016-9717-4

Hodgen, J., Oldenburg, R., \& Strømskag, H. (2018). Algebraic thinking. Developing Research in Mathematics Education, 32-45. https://doi.org/ 10.4324/9781315113562-4

Hunter, J., \& Miller, J. (2020). Using a culturally responsive approach to develop early algebraic reasoning with young diverse learners. International Journal of Science and Mathematics Education. https://doi.org/10.1007/s10763-02010135-0

Inan, C. (2015). Elementary school preservice teachers' competencies in the field of patterns under the process of scientific skills development. Universal Journal of Educational Research, 3(10), 663-670. https:/ / doi.org/10.13189/ujer.2015.031002

Kamol, N. (2005). A framework for characterizing lower secondary school students' algebraic thinking [Unpublished doctoral dissertation]. Srinakharinwirot University.

Kamol, N., \& Har, Y. B. (2010). Upper primary school students' algebraic thinking. In L. Sparrow, B. Kissane, \& C. Kurst (Eds.), Shaping the future of mathematics education: Proceedings of the 33rd Annual Conference of the Mathematics Education Research Group of Australasia (pp. 289-296). MERGA.

Kaput, J. J. (1999). Teaching and learning a new algebra. Mathematics Classrooms That Promote Understanding, Ccm, 133-155.

Kaput, J. J. (2008). What is algebra? What is algebraic reasoning? In J. J. Kaput, D. W. Carraher, \& M. L. Blanton (Eds.), ALGEBRA in the early grades. Taylor \& Francis Group.

Kieran, C. (2004). Algebraic thinking in the early grades: What is it. The Mathematics Educator, 8(1), 139-151.

Kieran, C. (2006). The core of algebra: Reflections on its main activities. In K. Stacey, H. Chick, \& M. Kendal (Eds.), The Future of the Teaching and Learning of Algebra The 12th ICMI Study (pp. 21-33). Springer. https://doi.org/10.1007/1-4020-8131-6_2

Kieran, C. (2011). Overall commentary on early algebraization: Perspectives for research and teaching. In J. Cai, \& E. Knuth (Eds.), Early algebraization (pp. 579-593). https://doi.org/ 10.1007/978-3-642-17735-4_29

Kriegler, S. (2007). Just what is algebraic thinking? Introduction to Algebra:TeacherHandbook, 1-11.

Kusumaningsih, W., Darhim, Herman, T., \& Turmudi. (2018). Gender differences in algebraic thinking ability to solve mathematics problems. Journal of Physics: Conference Series, 1013(1). https:/ / doi.org/ 10.1088/1742-6596/1013/1/012143

Kyriacou, C. (2009). Effective teaching in schools theory and practice. Stanley Thornes. https:/ / doi.org/10.1016/ j.vetpar.2010.08.020

Lentz, U. (2018). Algebraic thinking of sixth graders through the lens of multimodality [PhD thesis, The University of North Carolina at Charlotte].

Liberati, A., Altman, D. G., Tetzlaff, J., Mulrow, C., Gøtzsche, P. C., Ioannidis, J. P. A., Clarke, M., Devereaux, P. J., Kleijnen, J., \& Moher, D. (2009). The PRISMA statement for reporting systematic reviews and meta-analyses of studies that evaluate health care interventions: Explanation and elaboration. Journal of Clinical Epidemiology, 62(10), e1-e34. https://doi.org/10.1016/j.jclinepi.2009. 06.006

Lins, R. C. (1992). A framework for understanding what algebraic thinking is [Unpublsihed Ph.D. thesis. University of Nottingham]. http:/ / eprints.notting ham.ac.uk/13227/1/316414.pdf

MacGregor, M., \& Stacey, K. (1997). Students' understanding of algebraic notation: 11-15. Educational Studies in Mathematics, 33(1), 1-19. https:/ / doi.org/10.1017/CBO9781107415324.004

Magiera, M. T., van den Kieboom, L. A., \& Moyer, J. C. (2013). An exploratory study of pre-service middle school teachers' knowledge of algebraic thinking. Educational Studies in Mathematics, 84(1), 93-113. https: / / doi.org/10.1007/s10649-013-9472-8

Magiera, M., van den Kieboom, L., \& Moyer, J. (2017). K8 pre-service teachers' algebraic thinking: Exploring the habit of mind "Building rules to represent functions". Mathematics Teacher Education and Development, 19(2), 25-50.

Mason, J. (2008). Making use of children's powers to produce algebraic thinking. Algebra In The Early Grades, 2008, 57-94. https://doi.org/10.4324/ 9781315097435-4

Mulligan, J., Oslington, G., \& English, L. (2020). Supporting early mathematical development through a 'pattern and structure' intervention program. ZDM - Mathematics Education, 52(4), $663-$ 676. https:// doi.org/10.1007/s11858-020-01147-9

NCTM. (2000). Principles and standarts for school mathematics. The National Council of Teachers of Mathematics. 
Ntsohi, M. M. E. (2013). Investigating teaching and learning of grade 9 algebra through excel spreadsheets: A mixedmethods case study for Lesotho (Issue December). https:/ / scholar.sun.ac.za/handle/10019.1/85657

Obara, S. (2019). Pre-service teachers exploring the role of pattern-based reasoning in the context of algebraic thinking. Eurasia Journal of Mathematics, Science and Technology Education, 15(11). https:/ / doi.org/10.29333/ejmste/109262

Papadopoulos, I., \& Patsiala, N. (2019). When the "Tugof-War" game facilitates the development of algebraic thinking. International Journal of Science and Mathematics Education, 17(7), 1401-1421. https: / / doi.org/10.1007/s10763-018-9928-5

Pincheira, N., \& Alsina, Á. (2021). Teachers' mathematics knowledge for teaching early algebra: A systematic review from the mkt perspective. Mathematics, 9(20), 2590. https:/ / doi.org/10.3390/math9202590

Pitta-Pantazi, D., Chimoni, M., \& Christou, C. (2019). Different types of algebraic thinking: An empirical study focusing on middle school students. International Journal of Science and Mathematics Education, 18, 965-984. https://doi.org/10.1007/ s10763-019-10003-6

Pourdavood, B. R., McCarthy, K., \& McCafferty, T. (2020). The impact of mental computation on children's mathematical communication, problem solving, reasoning, and algebraic thinking. Athens Journal of Education, 7(3), 241-254. https:/ / doi.org/ 10.30958/aje.7-3-1

Radford, L. (2000). Signs and meanings in students' emergent algebraic. Educational Studies in Mathematics, 42(3), 237-268. https://doi.org/ 10.1023/A:1017530828058

Radford, L., \& Sabena, C. (2015). The question of method in a Vygotskian semiotic approach. In Approaches to qualitative research in mathematics education (Issue January 2014, (pp. 157-182). https://doi.org/ 10.1007/978-94-017-9181-6_7

Ralston, N. C. (2013). The development and validation of a diagnostic assessment of algebraic thinking skills for students in the elementary grades [PhD Dissertation, University of Washington].

Ralston, N. C., Li, M., \& Taylor, C. (2018). The development and initial validation of an assessment of algebraic thinking for students in the elementary grades. Educational Assessment, 23(3), 211-227. https://doi.org/10.1080/10627197.2018. 1483191

Rittle-Johnson, B., Fyfe, E. R., McLean, L. E., \& McEldoon, K. L. (2013). Emerging understanding of patterning in 4-year-olds. Journal of Cognition and Development, 14(3), 376-396. https://doi.org/ $10.1080 / 15248372.2012 .689897$
Rudyanto, H. E., Marsigit, Wangid, M. N., \& Gembong, S. (2019). The use of bring your own device-based learning to measure student algebraic thinking ability. International Journal of Emerging Technologies in Learning, 14(23), 233-241. https://doi.org/ 10.3991/ijet.v14i23.11050

Schliemann, A. D., Carraher, D. W., \& Brizuela, B. M. (2013). Bringing out the algebraic character of arithmetic: From children's ideas to classroom practice. Taylor \& Francis Group. https://doi.org/ $10.4324 / 9780203827192$

Schunk, D. H. (2012). Learning theories an educational perspective. Pearson.

Smith, J. P., \& Thompson, P. W. (2007). Quantitative reasoning and the development of algebraic reasoning. Algebra In The Early Grades, 95-132. https://doi.org/10.4324/9781315097435-5

Somasundram, P. (2021). The role of cognitive factors in year five pupils' algebraic thinking: A structural equation modelling analysis. Eurasia Journal of Mathematics, Science and Technology Education, 17(1), 1-12. https:/ / doi.org/10.29333/ ejmste/9612

Specht, B. J. (2005). Early algebra - Processes and concepts of fourth graders solving algebraic problems. CERME 4-European Research in Mathematics Education IV: Proceedings of the Fourth Congress of the European Society for Research in Mathematics Education, 4, 706-7016. http:/ / www.mathematik.uni-dortmund.de / erme/CERME4/CERME4_WG6.pdf

Stephens, A., Blanton, M., Knuth, E., Isler, I., \& Gardiner, A. M. (2015). Just say yes to early algebra! Teaching Children Mathematics, 22(2), 92. https://doi.org/ 10.5951/teacchilmath.22.2.0092

Syarifuddin, H., \& Atweh, B. (2022). The use of activity, classroom discussion, and exercise (ACE) teaching cycle for improving students' engagement in learning elementary linear algebra. European Journal of Science and Mathematics Education, 10(1), 104-138. https:/ / doi.org/10.30935/scimath/11405

Usiskin, Z. (1999). Conceptions of school algebra and uses of variables. In B. Moses (Ed.), The ideas of algebra, K-12 (Issue 5, pp. 8-19). NCTM.

van Amerom, B. (2002). Reinvention of early algebra. In K. Gravemeijer (Ed.), Developmental research on the transition from arithmetic to algebra (p. 352).

van den Kieboom, L. A., Magiera, M. T., \& Moyer, J. C. (2014). Exploring the relationship between K-8 prospective teachers' algebraic thinking proficiency and the questions they pose during diagnostic algebraic thinking interviews. Journal of Mathematics Teacher Education, 17(5), 429-461. https: / / doi.org/10.1007/s10857-013-9264-1

Venenciano, L. C. H., Yagi, S. L., Zenigami, F. K., \& Dougherty, B. J. (2020). Supporting the 
development of early algebraic thinking, an alternative approach to number. Investigations in Mathematics Learning, 12(1), 38-52. https:/ / doi.org/ 10.1080/19477503.2019.1614386

Walkoe, J. (2014). Exploring teacher noticing of student algebraic thinking in a video club. Journal of Mathematics Teacher Education, 18(6), 523-550. https: / / doi.org/10.1007/s10857-014-9289-0

Walkowiak, T. A. (2014). Elementary and middle school students' analyses of pictorial growth patterns. Journal of Mathematical Behavior, 33(1), 56-71. https:// doi.org/10.1016/j.jmathb.2013.09.004
Wilkie, K. J. (2016). Students' use of variables and multiple representations in generalizing functional relationships prior to secondary school. Educational Studies in Mathematics, 93(3), 333-361. https:/ / doi.org/10.1007/s10649-016-9703-x

$\mathrm{Wu}, \mathrm{Z}$. (2017). Effects of using problem of the week in teaching on teacher learning and change in algebraic thinking and algebra. ZDM - Mathematics Education, 49(2), 203-221. https:/ / doi.org/10.1007/ s11858-017-0844-x

\section{https://www.ejmste.com}

